\title{
Correction to: Atypical presentation of hemorrhagic shock in pregnancy: a case highlighting the developing field of emergency medicine in Israel
}

Baruch Berzon ${ }^{1 *}$, Michael Gleenberg ${ }^{1}$, Joseph Offenbacher ${ }^{2}$ and Debra West ${ }^{1}$

Correction to: BMC Emerg Med (2019) 19:70

https://doi.org/10.1186/s12873-019-0272-z

The original article [1] contained a misspelling in first author, Baruch Berzon's name which has since been corrected.

\section{Author details}

1Department of Emergency Medicine Ha-Refu'a St 7, Samson Assuta Ashdod Medical Center, 7747629 Ashdod, Israel. ${ }^{2}$ Albert Einstein College of Medicine, Department of Emergency Medicine at the Jacobi and Montefiore Hospitals 1400ham Pkwy S, Bronx, NY 10461, USA.

Published online: 15 January 2020

\section{Reference}

1. Berzon B, Gleenberg M, Offenbacher J, West D. Atypical presentation of

hemorrhagic shock in pregnancy: a case highlighting the developing field of emergency medicine in Israel. BMC Emerg Med. 2019;19:70. https://doi. org/10.1186/s12873-019-0272-z.

Full list of author information is available at the end of the article 